\title{
The Nature and Processes of IT-Related Change
}

\author{
Susan Gasson \\ Information Systems Research Unit \\ Warwick Business School \\ University of Warwick
}

Niki Holland

Transition Partnerships

\begin{abstract}
This paper presents the findings of an empirical survey of senior IT managers' perceptions of their company's approach to IT-related change in the UK. The survey was based upon a theoretically-derived framework for the classification of information systems development approaches; this is used to map trends in development approaches graphically. The findings of this study are also used to examine the feasibility of academic, business-process oriented approaches to ITchange strategies, which encourage high degrees of user-participation in the change process - an examination that has largely been missing from contemporary discussions of IT-related organizational change.

The paper thus has important implications for research and practice. Specifically, the findings suggest that the overall management approach to IT-related change is less critical to the extent of user-participation in the overall change-process than is the question of whether system development is performed in-house or by a third party. Additionally, these findings demonstrate the overriding preponderance of technical/functional approaches to IS development during the system design stage of development, regardless of whether a business/organizational or a technical/functional emphasis is given to the IT-related change overall.
\end{abstract}




\section{INTRODUCTION}

The academic community has recently been the center of a debate about the nature of IT-related change. While academics would see IT-related organizational change as being most closely aligned with the organization's business processes and strategic direction (Galliers 1987; Scott Morton 1991), IT-related change is thought to be perceived, within organizations, as a primarily technical task (Hornby et al. 1992; Hopker 1994). The study described here set out to explore this perception. Do managers see IT-related change as primarily a technical problem? Do the tools and approaches used to support IT change-analysis and IT system development support a business-oriented or a functional/technical approach to change? To what extent do users participate in the processes of IT-related change?

\section{THE THEORETICAL FRAMEWORK}

Much of the prior research in approaches to IT-related change has either treated the organizational and social factors of IT change as a "black box," concentrating upon exploring what methods are used and how these methods are applied (Wynekoop and Russo 1993; Hornby et al. 1992; Hopker 1994; Hardy, Thompson and Edwards 1994) or has treated the development approach as a "black box," examining social and organizational factors, such as user-participation (Kappelman and McLean 1992; Morley 1993), developer attitudes to users (Hedberg and Mumford 1975), work-group organization (Mumford and Henshall 1983; Heller 1987), or the politics of interest-groups (Markus and Bjørn-Andersen 1987). Little empirical work can be found investigating the middle-ground: that bifurcation of interest between organizational behaviorists and computer-scientists, which lies in the interactions of methods, processes and organization. This paper addresses that middle ground by discussing the results of an exploratory survey into the relationship between approaches to IT-related change, the methods used to develop the Information Systems involved in the change, and the extent to which users of the target system participate in the processes of change.

This investigation was based upon a framework for the classification of approaches to Information System (IS) development which attempts to bring together the elements of both technical and organizational change. This framework, shown in Figure 1, was presented in detail in an earlier paper (Gasson 1994). The theoretical background to the framework is summarized briefly below.

The framework in Figure 1 was derived from Leavitt's (1972) "diamond" model of organizational change. Leavitt presents the four factors of the model as the objects of organizational change and sees them as interdependent: change in any one results in changes in the others. If information systems development is seen as organizational change, then the four factors of this model can be seen as the objects of information systems development. Choices between pairings of these objects may thus be helpful in characterizing differing approaches to systems development; an interpretation of this is shown in Figure 2. The interactions between the four factors of Leavitt's model form six "dimensions" of action along which information systems development approaches may be modeled: technology-structure, technology-people, technology-task, task-people, structure-people, and task-structure. 


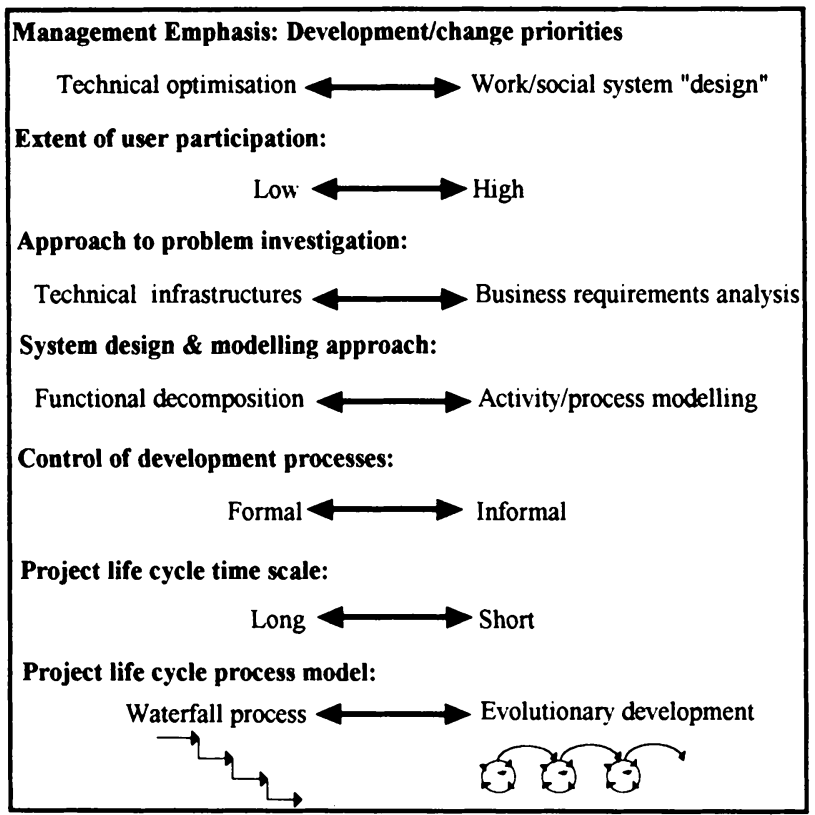

Figure 1: Framework for the Classification of Approaches To IS Development

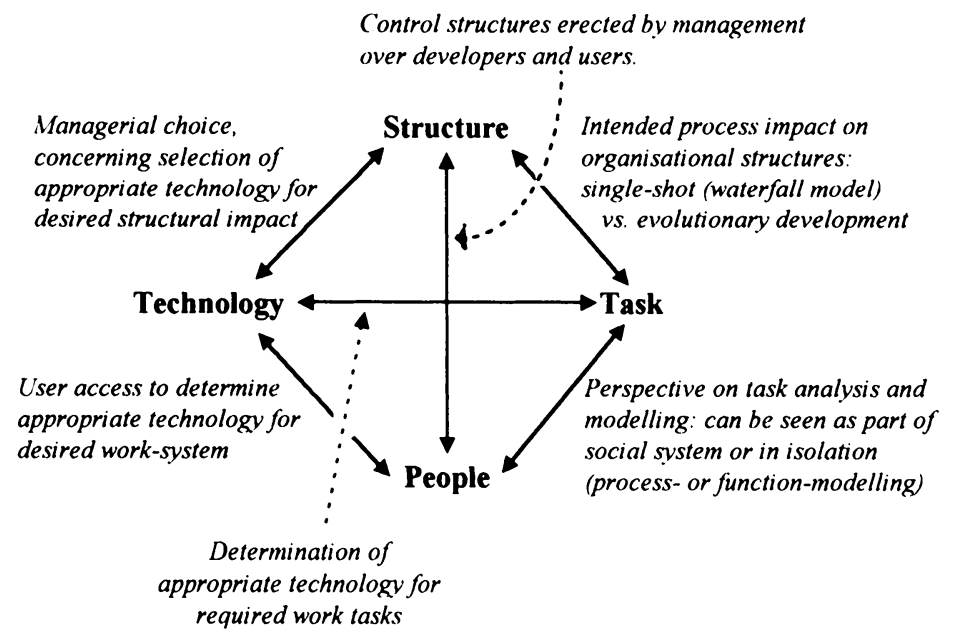

Figure 2: Approaches to Information Systems Development as Organizational Change (adapted from Leavitt 1972) 
A previous dichotomy of systems development between datalogical and infological perspectives (c.f. Methlie 1980) has more recently been expanded to a trichotomy between the organizational context, the conceptual/infological (or language) context and the datalogical/technical context (c.f. Lyytinen 1987; Iivari 1987). Lyytinen models approaches to systems development as lying on the spectra between the extremes of contexts: for example, life-cycle models are shown as lying between the language and technical contexts. Lyytinen's language context can be seen as embodying both modeling conceptual/cognitive knowledge and signifying human action. Although crude, the terms "people" and "task" may be used to represent the dual objects of this language context; the framework can thus be seen to fit with existing thinking about the domains of information systems development.

Coupled with the above interpretation was a need to encompass the dichotomy between "hard" and "soft" systems thinking proposed by Checkland (1981). Hard systems thinking, typified by systems engineering or structured systems analysis, sees the system development problem as relatively well-defined: the methodological objective is to satisfy the given requirements through the technical implementation of a closed system. In contrast, soft systems thinking sees the problem situation as ill-defined: the target object system is perceived as part of a wider, social and political system and the task of the analyst is to determine desirable and feasible change by exploring and expressing the problem situation. In hard systems thinking, the concern is with the properties of a physical (technical) system and it is believed that human behavior can be modeled using rule-based systems, so the problem is analyzed, by defining system objectives and requirements. In soft systems thinking, the concern is with a system of human activity, so the problem is expressed, by examining elements of structure and process and their mutual relationship.

The six dimensions of the framework were operationalized, using constructs from systems development practice, in such a way that one extreme of each dimension represented hard systems thinking and the other extreme represented soft systems thinking (the framework has been constructed so that hard approaches align with the left axis of the model spectra and soft approaches align with the right axis). The resulting dimensions are given in Figure 3.

When the framework was applied in a pilot study, it was discovered that the long, systems lifecycle approach versus the short, evolutionary approach was insufficient to define all projects, as some were long, evolutionary projects (corresponding to staged functional delivery, rather than an evolutionary approach where the structural impact of the system may change with evolution) and some were short waterfall approaches (where the system development did not have significant impact on the organization). To remove ambiguity from the application of the framework in practice, it was decided to split this element into two dimensions, the time dimension and the process-model dimension, giving seven dimensions to the framework.

The expected relationships (from the literature) between these variables are shown in Figure 4. In most of the literature in this area, two of the seven development approach framework dimensions are singled out for special attention: the management approach to IT-related change (c.f. Galliers 1987; Checkland and Scholes 1990; Scott Morton 1991; Benjamin and Levinson 1993) and user participation in the processes of IT-related change (c.f. Kappelman and McLean 1992; Morley 1993; Hirschheim and Klein 1989, 1992, 1994). 


\begin{tabular}{|l|c|}
\hline \multicolumn{1}{|c|}{ Leavitt's Model } & \multicolumn{1}{|c|}{ Operationalized Concepts } \\
\hline & hard \\
\hline technology-structure & technical optimization $\leftrightarrow$ work \& social system design \\
\hline technology-people & low user participation $\leftrightarrow$ high user participation \\
\hline technology-task & $\begin{array}{c}\text { top-down, technical approach } \\
\text { to problem investigation }\end{array} \leftrightarrow \begin{array}{l}\text { bottom-up, task approach to } \\
\text { problem investigation }\end{array}$ \\
\hline task-people & $\begin{array}{r}\text { function-oriented approach to } \leftrightarrow \text { system design } \\
\text { work-process orientation to } \\
\text { system design }\end{array}$ \\
\hline structure-people & $\begin{array}{c}\text { formal, system specification } \\
\text { orientation to development } \\
\text { project management }\end{array}$ \\
\hline task-structure & $\begin{array}{l}\text { informal user-satisfaction } \\
\text { orientation }\end{array}$ \\
\hline & $\begin{array}{r}\text { long, waterfall approach to } \\
\text { systems development } \leftrightarrow \text { short, evolutionary approach } \\
\text { to systems development }\end{array}$ \\
\hline
\end{tabular}

Figure 3: The Six Dimensions of the IS Development Approach Framework, Operationalized from the Interactions of Leavitt's (1972) Diamond Model

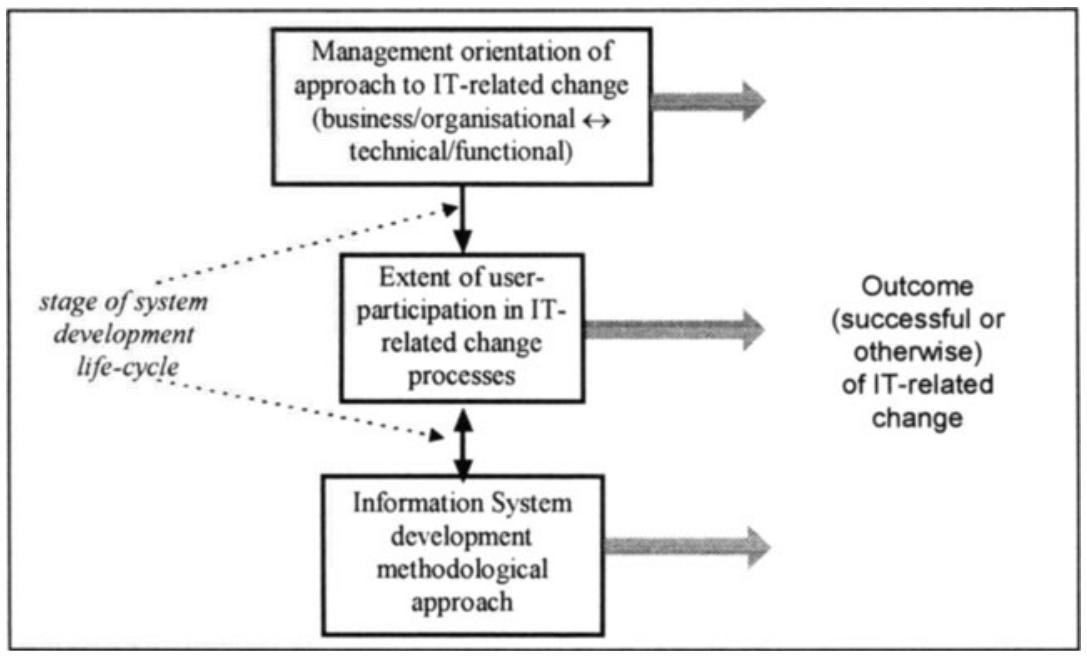

Figure 4: Proposed Relationships among Research Variables 
The other five dimensions can be considered representative of the factors considered in the literature on development methodologies (c.f. Boehm, Gray and Seewalt 1984; Boehm 1988; Avison and Fitzgerald 1988; Avison and Wood-Harper 1990; Jayaratna 1994). The shadowed lines show relationships which were not investigated by this study, but justify the selection and separation of these variables. The dotted lines show a modifying influence: the stage of the system development life-cycle (SDLC), as it was discovered in a previous case study (Gasson 1995), that the extent of user-participation in information system development was likely to vary with the stage of the SDLC. The SDLC was split according to the three stages given in Budde and Zullighoven (1983): requirements specification, systems design, coding and implementation.

Jayaratna (1988) argues that process-oriented methods are appropriate for less well-structured organizational contexts. It can be argued that, as organizations have to increasingly respond to highly complex and turbulent product-market environments, all organizational contexts are becoming less well-structured and a functional/technical orientation is no longer appropriate. Argyris (1987) argues that designing for adaptive behavior is central to any effective approach to information system development. One would thus expect managerial approaches to IT-related change to be primarily business and process oriented.

Kumar and Bjørn-Andersen (1990) state that the prescription of a particular methodology incorporates into the design process "the ontological assumptions about what constitutes reality and the epistemological assumptions about how to conduct the ISD enquiry." They proceed to argue that the designers' value-systems are largely influenced by the choice of ISD methodology. This methodological determinism is challenged by Markus and Bjørn-Andersen, who argue that designers' existing value systems influence the selection of development methodologies. IS development methods are largely based upon a waterfall model and emphasize technical/functional optimization because technical expertise is the basis of IS professionals' power (Markus and Bjørn-Andersen 1987; Hornby et al. 1992). If managers' approaches emphasize a business orientation, one would expect the emphasis taken by system development approaches to be in conflict with that taken by organizational managers and to lack direct influence from the management approach.

Eason (1982) and Corbett, Rasmussen and Rauner (1991) argue that the extent of userparticipation is directly influenced by the methodological approach taken to IS development. A traditional, (waterfall process-model based) development methodology excludes users, as their only contact with the process is via the validation of documents which they may not be in a position to understand fully. An evolutionary, prototyping approach to development, on the other hand, provides users with learning opportunities throughout the development process, permitting them to contribute to design decisions in an informed and powerful way. Thus it could be expected that the extent of user-participation is directly related to the type of methodology in use. However, in practice methodologies are not often used in the manner intended: IS professionals use tools and methods from a variety of methodologies, adopting a contingency approach to method customization (Vitalari 1984; Hornby et al. 1992; Hardy, Thompson and Edwards 1994). Users may be permitted to participate to a high degree in system development projects which use traditional methodologies (Hardy, Thompson and Edwards 1994; Hopker 1994) and may be excluded from system development which uses evolutionary prototyping approaches (Gasson 1995). A more detailed framework than is provided by a description of the methodology is 
therefore required to examine the overall approach to IS development. There is a need for a bridging framework between theory and practice (Keen 1987) which assesses the approach to information systems development and enables a comparison of the actual development approach to that intended by the methodology.

\section{RESEARCH METHOD}

An initial case study investigation (Gasson 1995) supported the findings of Hornby et al. and of Hopker that prevailing approaches to IS development were driven by technical considerations and that user participation in these technically-driven processes was problematic. An exploratory questionnaire was devised to explore current approaches to Information System development as part of strategic IT-related change, to investigate the relationships shown in Figure 4 and to test the utility of the research framework, given in Figure 1, for the classification of approaches to IS development. This survey is part of a wider exploration of these issues which adopts methodological pluralism (Hirschheim 1992) in order to obtain a multi-perspective understanding of IS development in an organizational context.

The survey method was used to determine senior management perspectives across a wide range of organizations, to ascertain whether development practice is changing to a more business/process oriented approach and the impact that this has upon user participation in IS development processes. While a survey was judged the best method to collect data from a large number of organizations, the research instrument was not intended to be used for quantitative measurement, but as a qualitative framework for assessing IS development practice in the UK. The data collected represents a subjective, single stakeholder perspective on the practices of IS development, rather than a quantitative assessment of IT change approaches.

When piloting the questionnaire, it was found that the framework permitted ambiguities and some questions (pertaining to the system development life-cycle model and the extent of userparticipation) were rephrased to use clear examples of meaning - this necessarily compromised the use of a consistent scale for all dimensions of the framework. The survey questions are given in the appendix. As this study formed part of a larger questionnaire on management aspects of IT-related change, it was not possible to actively seek comments from respondents. However, managers did make comments freely in the spaces on the questionnaire, providing useful feedback on the utility of the terms used to interpret the research framework. Three questionnaires were sent to large UK companies: to a senior human resource manager, to a senior line manager and to a senior IT-function manager. This paper examines the responses of the senior IT-function managers to those questions pertaining to the approach used to accomplish IT-related change.

Managers were asked to classify their seniority in the function they represented on a scale of 1 to 7 , where 1 was a junior manager/specialist and 7 was the head of the function. The average management level given was 5.59 , with $81 \%$ (26) of the respondents being at management level 5 or above. Respondents at level 3 or below were excluded from the study, as a strategic overview was required. However, there is the danger that senior managers may not know what methods and approaches were taken, in detail. When the data was judged to be insufficiently detailed, or when sections were left blank (or returned marked "don't know"), that response was excluded from the analysis. We received 49 valid responses. Of these, only 32 companies had 
performed Information System development as part of the change process; 17 companies had contracted-out IS development to a third party.

For the purposes of this study, the system development life-cycle was split into three phases: system requirements analysis, system design and modeling, and system implementation and testing. The Information System development approach was determined using the classification framework given in Figure 1. Responses to questions 1 and 2 (Appendix) were used to classify the companies with respect to the six-stage model of stage of growth with respect to IT (Galliers and Sutherland 1991). This was a fairly subjective assessment, determined from the organization's current use of IT and was performed with less detail than that recommended by Galliers and Sutherland, as the need to keep the survey of manageable length indicated a focus on the primary interest of the survey, which was the processes of IS development in the context of ITrelated organizational change. However, it was required to determine that the respondents were at a relatively advanced stage of growth, in order to determine whether their responses represented companies that have a reasonable extent of experience with IT-related change and could therefore be considered representative of "good practice" in the UK. This was found to be so: $86 \%$ of all responses were from companies at stage 4 to 5 , the other $14 \%$ were from companies considered to be at an advanced point in stage 3 - the transition-point between managing the technology and managing corporate information (Galliers and Sutherland 1991). Responses to questions 3 to 7 were used to classify responses according to the research models given above.
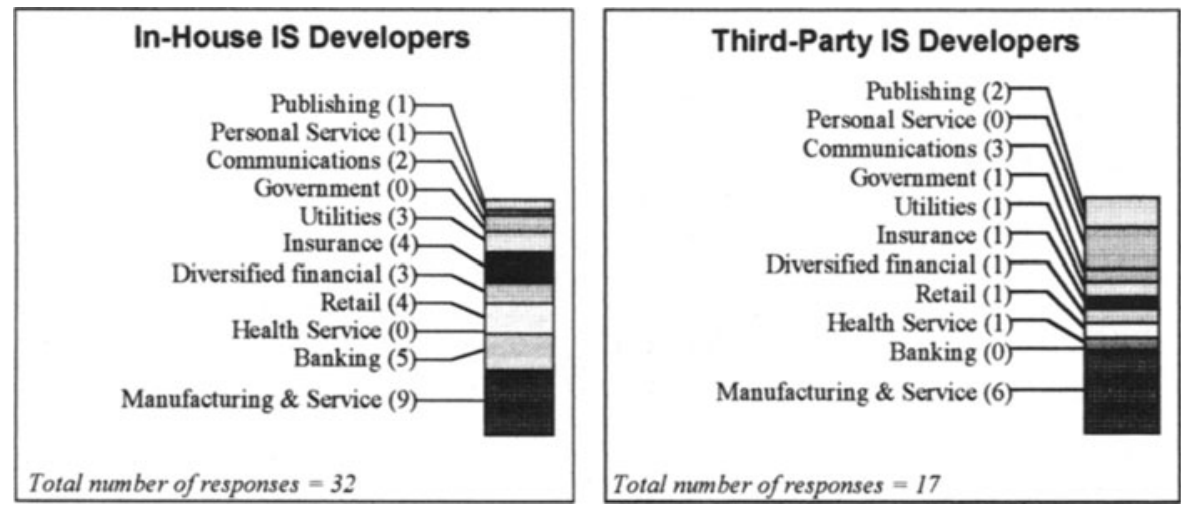

Figure 5: Profile of Survey Respondents (Number of Firms in Each Category in Brackets)

A postal survey is not ideal for this type of study: it provides a wide picture without providing a rich picture. However, it does have the advantage that a relatively large amount of data may be collected fairly quickly, for an investigative study. For this reason, the survey method was used to investigate whether perceptions of the IS development process acquired through the earlier case study applied to a wide range of contemporary UK practice. Because the research instrument was subjective, no advanced statistical analysis was performed: the results presented 
here are summary results and exploratory, rather than confirmatory, in nature. The findings do, however, provide a rich and interesting picture of IS development in large UK companies.

\section{FINDINGS OF THE SURVEY}

A higher proportion of those companies that contracted out their IS development to a third party (76\%) took an evolutionary approach to IS development than the proportion of those companies that performed their own IS development in-house (59\%). This may be because companies that perform their own development do so for more complex IT change - it was not possible to ascertain if this was the case from the responses available. However, the companies that contracted out IS development had comparable average project duration (2.76 years) to those companies that performed their own development ( 2.47 years), so the project complexity of the two groups' development projects is likely to be comparable, as the time scales are comparable.

Respondents were asked what methods and tools were used for project management and for system development, at the requirements analysis, system design and implementation stages of the system development life-cycle. Responses from this, open, question were coded: the results from the sub-population who performed in-house IS development are given in 6 . There was a high level of non-reporting for the sub-population which contracted out IS development presumably they did not know what tools had been used.

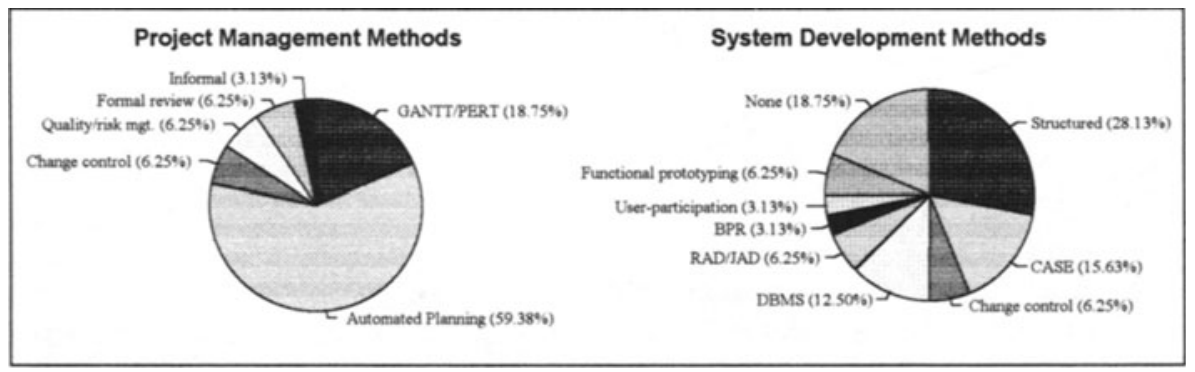

Figure 6: Tools Used For Project Management and For System Development

It is noticeable that $78 \%$ of respondents reported the use of an automated or manual projectscheduling tool. The functions of project management have so clearly become synonymous with scheduling and resource-allocation that managers do not use any tools to support other areas of responsibility such as facilitating and recording user-input to the development process. Even when asked to identify tools used for system development purposes, only one company reported using a tool which supported user-participation. This finding would tend to reinforce previous findings in this area, which report that IS development is largely seen as a scheduling management problem and as a functional/technical responsibility (Hornby et al. 1992).

One of the main findings, which supports previous studies performed in this area (c.f. Hornby et al. 1991; Hopker 1994), is that the approach to system design and modeling is significantly 
"harder" (i.e., with a more functional/technical orientation than a business/process orientation) than the management approach or the approach to problem investigation. Respondents were asked to rate their approach to the overall emphasis of the change (the management approach of the research framework), the approach to system requirements definition (the problem investigation approach of the research framework) and the approach taken to system design and modeling (the system design and modeling approach of the research framework). The results are presented in Table 1, where the given figures are for respondents who rated their approach at level 5, 6 or 7 on a 7-point scale for the three emphases (i.e. those respondents who took a more business/process orientated approach to change than a functional/technical orientated approach).

\begin{tabular}{|l|c|c|c|}
\hline & $\begin{array}{c}\text { Overall Emphasis of } \\
\text { Change }\end{array}$ & $\begin{array}{c}\text { Approach to System } \\
\text { Reqs. Definition }\end{array}$ & $\begin{array}{c}\text { Approach to System } \\
\text { Design \& Modeling }\end{array}$ \\
\hline $\begin{array}{l}\text { In-house IS Development: } \\
32 \text { valid responses }\end{array}$ & $22(69 \%)$ & $28(87 \%)$ & $9(28 \%)$ \\
\hline $\begin{array}{l}\text { Third-Party IS Development: } \\
17 \text { valid responses }\end{array}$ & $6(35 \%)$ & $11(65 \%)$ & $5(29 \%)$ \\
\hline
\end{tabular}

Table 1: Proportion of Respondents Taking a "Soft" Management, Problem Investigation and System Design Approach

The proportion of companies taking a business/process orientation to IT change declined markedly at the system design and modeling stage of the system development life-cycle, for both companies who performed in-house IS development and companies who contracted IS development to a third-party. Another interesting finding is that the proportion of companies who contracted out their IS development which took a business/process oriented approach to managing IT-related change is almost half the proportion of companies who performed their own IS development.

To provide a consistent assessment of the extent of user-participation between responses, respondents were asked whether certain mechanisms had been used to involve users in the IS development process. These mechanisms are listed in question 7 (Appendix); of these, the mechanisms which encourage the highest degree of user participation are given in Table 3. Although this type of question is still open to interpretation, it does remove a level of subjectivity associated with a "high-low" scaling response mechanism. The extent of user-involvement varied, as predicted, with the system development life-cycle, with the lowest reported involvement being at the system design and modeling stage. Table 2 summarizes the responses: a "high" level of user involvement is ranked as a company using one of the two user-participation mechanisms that most permit users to participate meaningfully and equally in the IS development process, at various stages of the system development life-cycle. 


\begin{tabular}{|l|c|c|c|c|}
\hline & $\begin{array}{c}\text { System } \\
\text { Requirement } \\
\text { Analysis }\end{array}$ & $\begin{array}{c}\text { System Design \& } \\
\text { Modeling }\end{array}$ & $\begin{array}{c}\text { System } \\
\text { Implementation \& } \\
\text { Test }\end{array}$ & $\begin{array}{c}\text { System } \\
\text { Operation }\end{array}$ \\
\hline $\begin{array}{l}\text { In-house IS Development: } \\
32 \text { valid responses }\end{array}$ & $28(88 \%)$ & $17(53 \%)$ & $27(84 \%)$ & $21(66 \%)$ \\
\hline $\begin{array}{l}\text { Third-Party IS Development: } \\
17 \text { valid responses }\end{array}$ & $8(47 \%)$ & $1(6 \%)$ & $5(29 \%)$ & $9(53 \%)$ \\
\hline
\end{tabular}

Table 2: Proportion of Respondents Reporting a High Level of User Participation at Various Stages of System Development Life-Cycle

What is particularly significant about these results is the very high level of user-participation shown by users in companies performing their own IS development and the relatively low levels shown in companies that contracted out IS development to third parties. The proportion of companies using the two highest-ranked mechanisms for user-involvement at each stage of the system development life cycle are shown in Table 3. Of companies that performed IS development, $81 \%$ reported having users as members of the IS development team at the system requirements analysis stage, although only $34 \%$ of these companies reported that users had been trained in the use of development tools at the system design and modeling stage.

\begin{tabular}{|l|c|c|}
\hline & IS Developers & $\begin{array}{c}\text { Third-Party } \\
\text { Development }\end{array}$ \\
\hline Participation of users as development team members & $81 \%$ & $47 \%$ \\
\hline Joint design with users & $63 \%$ & $6 \%$ \\
\hline User training in development tools & $34 \%$ & $6 \%$ \\
\hline Use of evolutionary systems prototypes & $31 \%$ & $0 \%$ \\
\hline User workshops to discuss design changes & $50 \%$ & $18 \%$ \\
\hline User-directed testing schedules & $75 \%$ & $18 \%$ \\
\hline User-redesign of work processes & $28 \%$ & $18 \%$ \\
\hline Modifications to system design to support business applications & $63 \%$ & $47 \%$ \\
\hline
\end{tabular}

Table 3: Proportion of Respondents Using Highest-Ranked User-Participation Tools at Each Stage of System Development Life Cycle

One of the most interesting findings of the survey as a whole was that $88 \%$ of the sample responded that user-consultation and involvement helped a great deal (i.e., ranked this factor as 5,6 or 7 on a 7 -point scale), whereas only $72 \%$ of the sample responded that approaches to planning and project management helped a great deal; these findings are shown in Table 4 . This 
is significant, as it contradicts the finding that IT-related change is mainly driven by functional/technical considerations (Homby et al 1992), in which case one would expect planning and project management approaches to be valued more highly than user-involvement. Additionally, both user-consultation and planning and project management were rated less highly by companies that contracted-out IS development, perhaps reflecting both the lower levels of user-participation discussed above and also the higher degree of delegation of planning and project management which is performed by companies who contract-out system development.

\begin{tabular}{|l|c|c|}
\hline & User-Consultation & $\begin{array}{c}\text { Planning \& Project } \\
\text { Management }\end{array}$ \\
\hline $\begin{array}{l}\text { In-house IS Development: } \\
32 \text { valid responses }\end{array}$ & $28(88 \%)$ & $23(72 \%)$ \\
\hline $\begin{array}{l}\text { Third-Party IS Development: } \\
17 \text { valid responses }\end{array}$ & $11(63 \%)$ & $11(65 \%)$ \\
\hline
\end{tabular}

Table 4: Proportion of Respondents Ranking User-Consultation or Planning and Project Management as "Helped a Great Deal"

We is intend to explore whether the development methods used also affected the degree of userparticipation in more detailed investigations; it is probable that many more tools and methods are used in support of development processes than are known to senior IT managers.

\section{REFLECTIONS ON THE USE OF THE RESEARCH FRAMEWORK}

The research framework (given in Figure 1) was useful in that it helped to structure areas for exploration in the questionnaire and gave a reasonably consistent analysis tool with which to classify approaches to IT change and system development. Figure 7 shows the research findings mapped onto the framework.

This framework gives a clear, graphical comparison of the two sub-populations: those companies who developed Information Systems in-house and those companies who contracted IS development to third-parties. It also clearly illustrates variations in companies' approach to IS development at various stages in the system development life-cycle - there is a clear swing to the left of the model (the "hard" side of the continuum) at the system design and modeling stage. It can also be seen that project control approaches are much harder than the emphasis intended for the overall IT-related change. However, it should be noted that the project control measure is the least reliable of this study - it was obtained from analysis of the reported methods for project management and of answers to open questions as to what the respondent felt that they did well or badly. The process-model dimension was also a blunt tool, as applied in this survey, as respondents were asked to select one of two alternatives: single-stage or evolutionary. 


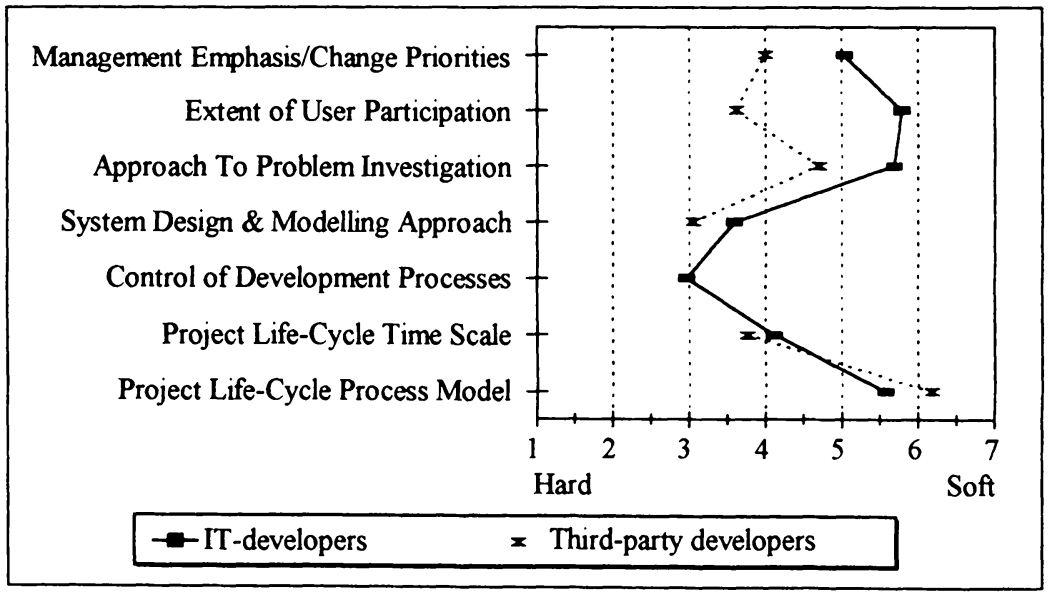

Figure 7: Research Findings Mapped onto the Research Framework

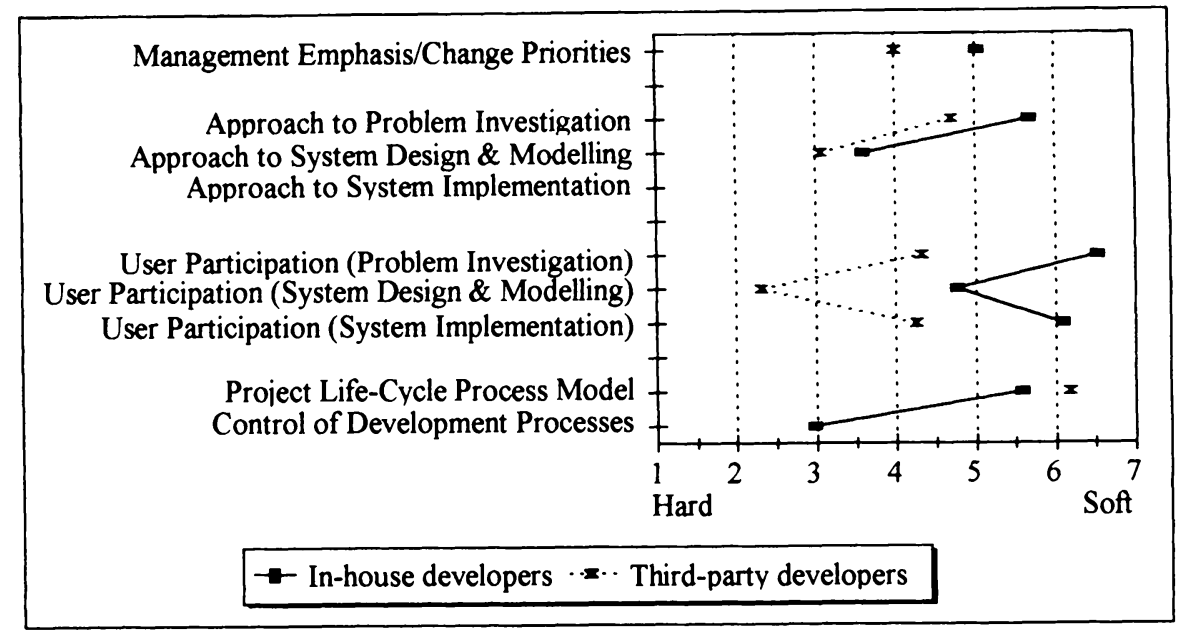

Figure 8: Research Findings Mapped onto Revised Research Framework 
During the design of this study, it was felt that the research framework could be revised to give a better indication of user participation at different stages of the system development life-cycle. The results have been mapped on the revised framework in Figure 8. This is more informative, as the extent of user-participation can be compared to the approach to system development at the same stage of the system development life-cycle. (It was originally intended to use the overall management emphasis as a proxy for the approach to system implementation; there was later felt to be insufficient justification for this). The patterns are telling: both the "soft-ness" of the approach to development and the extent of user-participation in that stage of development decline rapidly from the problem investigation/requirements analysis stage to the system design and modeling stage of the system development life-cycle. This is true for both in-house developers and third-party developers. However, while user-participation for in-house developers is higher than would be predicted from the softness of the approach to information systems development at that stage of the system development life-cycle, user-participation for development that was contracted to third parties is lower than could be predicted. This framework gives a helpfully clear identification of trends in approaches to IS development.

The research framework described has provided a clear visual representation of overall trends in Information System development practice; however, the operationalization of the framework needs further work in the context of case study investigations. The framework is not considered complete. The duration of the project did not prove helpful in gauging whether the project was evolutionary in the sense that user-feedback was used as input to the next evolution or evolutionary in the sense that technical developers delivered an incremental set of system functions; this dimension has been removed from the revised model. One of the survey respondents commented that "we involved the users in the selection of new systems and implementation, which is unique in my experience." A feeling of pride or uniqueness in permitting user-participation in various ways was quite frequent among respondents' comments and raises the issue (also identified in Gasson 1995) of the perceived legitimacy of user-participation in information systems development processes. This dimension could be helpful in identifying the "theory-in-use" rather than the "espoused theory" (Argyris and Schon 1978) of information systems development. It was also felt, following the survey, that the dimension of project control was ambiguous - it may be more useful to split this into two dimensions: (I) a Loose-Rigid control dimension and (ii) a Devolved-Centralized organizational structure dimension. However, with these modifications, the framework provides a clear structure for the classification of development approaches and it is felt that this will prove of immense use when using interview techniques and case study observations, especially as it is can be used as a diagram-based method of communication - IT professionals are accustomed to using such methods and this framework may elicit richer communication than verbal research instruments; it also communicates results to the IT profession much more clearly than numerical analysis, so may permit a higher transfer of research recommendations to industry practice.

\section{CONCLUSIONS}

It was discovered that the overall management perspective of IT-related change is to see it primarily as a business/organizational change, with the exploitation of technology as a secondary consideration. While the initial driver may be a change in technology, the system requirements analysis stage of the system development life-cycle is overridingly seen as being pertinent to 
business requirements rather than to technical infrastructures. However, once the system design and modeling stage begins, this business process emphasis is subsumed by the technically-driven approaches used by IS professionals.

User-participation varied significantly at different stages of the system-development life-cycle. Users are involved heavily at the implementation stage of the IT change. However, research in the area of user participation has shown that user involvement at this stage is mainly token: the system design will, by this point, have become "frozen" and the system requirements will have been specified formally at a much earlier stage (Eason 1982). The user therefore has little influence, except to change small, operational aspects of the system. Its scope and its effect on their work and their experience of the business/process support from the IT system cannot be affected at this stage in the change process. However, the findings were positive, in that attitudes to users are positive: $88 \%$ of respondents felt that user-involvement in the change had helped a great deal - a higher percentage than those who felt that project management and planning had helped a great deal.

Users of systems which were developed in-house stood a much higher chance of being permitted to participate in system development than potential users of systems developed by a third party. However, as for the development approach, user-participation declined markedly during the system design and modeling stage - the stage when their input could most affect the form of the new system and its impact upon the way in which their work is structured.

If one looks at the tools used for system development, these are overwhelmingly geared toward the control and support of technical aspects of the system under development, which could explain the low level of user-participation at this stage of the system development life-cycle.

There did appear to be a link between the orientation of the approach emphasized by the senior IT manager and the degree of user-participation, as predicted in the research model. With a subjective research instrument, it is not feasible to attempt to quantify the strength of this link, but there is sufficient evidence to suppose that there is a dependency relationship. This would also be supported by the ranking of user-involvement as "helping a great deal" by a significantly higher proportion of respondents than that which ranked planning and project management approaches as "helping a great deal."

\section{IMPLICATIONS FOR FUTURE RESEARCH AND ORGANIZATIONAL PRACTICE}

This study did not analyze in detail the type of Information System that formed the basis of the "major IT-related organizational change" about which respondents were asked to provide information. There may be a link between the type of system being changed or introduced and the approach taken to manage that change: this needs further investigation. There was a high degree of variation in IT managers' interpretations of the phrase "major IT-related organizational change," so the organizational impact of the reported IT-related change would have been much greater for some organizations than for others. 
The two most significant findings are that the level of user-participation is markedly higher at all stages of development for in-house Information System development than for third-party development and that both the degree of user-participation and the extent to which organizational and business factors are considered as high priority decline significantly at the system design and modeling stage of the system development life-cycle.

The first of these findings needs further investigation in terms of the type of system under development. Are users permitted to participate less in third-party IS development because their participation would be inappropriate for this type of system (which perhaps requires little human interaction) or are users excluded because of geographical constraints? At a superficial level, it would appear that the types of system where development was contracted out to third parties were more concerned with IT-infrastructure reorganization, whereas those developed in-house were more concerned with the reorganization of business processes. From an analysis of the brief system and impact details given by respondents, there is some evidence to support the theory that contracted-out systems were less radical in terms of their impact on the organization than those developed in-house and often took the form of a purchased package or a new IT infrastructure which was implemented by specialists in that technology. Given that the nature of many of the systems whose development was contracted out was a change in internal communications or software infrastructures, such as new electronic-mail systems, it would be expected that users would be encouraged to participate more, not less, than for the changes reported for those companies developing systems in-house. If user-participation is limited to applications that directly affect users' day-to-day tasks and not seen as legitimate for infrastructure systems which indirectly affect them, there may be adverse implications for the supportiveness and productivity of the working environment. It may be that the issue of legitimacy is critical here and the respondent who proclaimed his company's uniqueness in involving users in the selection of new systems is an exception. Most organizations may see IT-related change as driven by technical considerations and involve users only when radical business or organizational change is required as a pre-requisite to technical change.

The second finding confirms trends found in previous studies of the system design stage of the system development life-cycle, when examined in isolation from other stages (c.f. Hedberg and Mumford 1975; Curtis, Krasner and Iscoe 1988). An examination of changes in approach over the system development life-cycle is required in far more detail. Again, the issue of legitimacy is seen as critical: Gasson (1995) found that both developers and users perceived information system design and modeling to lie in the technical domain, excluding the infological and organizational domains, even when the development process had been designed explicitly around emancipatory, evolutionary prototyping. System requirements are only partially known at the start of the design and modeling stage: they are explored and may be discounted or redefined through the processes of system design. Any definition of the system which emerges from this stage may be very different from that intended by users, but users have the least input to the processes of exploring and understanding system requirements at the design stage. While the overall system objectives are defined during the problem investigation/system requirements stage, the form of the eventual system, determining its impact upon users and organizational effectiveness, is decided during the system design and modeling stage. Exclusion of users at this stage must be detrimental to the system outcome: even if users are permitted to participate in system implementation and testing, the design has been frozen by this point and users' scope for 
change of the system will be limited to requesting changes to system functions that do not work, rather than those that do not work in a manner supportive of their desired work environment.

However, the overall business/organizational emphasis accorded to IS development by senior managers gives hope for those academics who have been attempting to "convert" IT managers to a business/organizational orientation! It is clear that there is a "take-over" of the processes of IT-related change at the system design stage by IT-professionals (analysts, designers and programmers), which gives functional/technical factors higher priority than business/organizational factors. There follows a set of research questions about how this process happens, which domains and objects of IS development are considered legitimate by different development stakeholders and whether the outcome is less effective, in matching organizational requirements, than if business/organizational factors had been prioritized. It is probable that the trend to a hard development approach during the system design stage of the system development life-cycle is undesirable, in terms of outcome. These areas needs further investigation in more detailed studies.

\section{REFERENCES}

Argyris, C. "Some Inner Contradictions In Management Information Systems'." In R. D. Galliers (Editor), Information Analysis. Reading, Massachusetts: Addison-Wesley, 1987.

Argyris, C., and Schon, D. A. Organizational Learning: A Theory of Action Perspective. Reading, Massachusetts: Addison-Wesley, 1978.

Avison, D. E., and Fitzgerald, G. Information Systems Development: Methodologies, Techniques and Tools. Oxford: Blackwell Scientific Publications, 1988.

Avison, D. E., and Wood-Harper, A. T. Multiview: An Exploration In Information Systems Development. Oxford: Blackwell Scientific Publications, 1990.

Benjamin, R.I., and Levinson, E. “A Framework for Managing IT-Enabled Change." Sloan Management Review, Summer 1993, pp. 23-33.

Boehm, B. W. “A Spiral Model Of Software Development And Enhancement." IEEE Computer Journal, May 1988.

Boehm, B. W.; Gray, T. E.; and Seewalt, T. "Prototyping Versus Specifying: A Multiproject Experiment." IEEE Transactions on Software Engineering, Volume SE-10, Number 3, 1984, pp. 290-302.

Budde, R., and Zullighoven, H. "Socio-Technical Problems of System Design Methods." In U. Briefs, C. Ciborra, L. Schneider (Editors), Systems Design For, With and By The Users. Amsterdam: North-Holland Publishing Company, 1983.

Checkland, P. Systems Thinking, Systems Practice. Chichester: Wiley, 1981 
Checkland, P., and Scholes, J. Soft Systems Methodology in Action. Chichester: Wiley, 1990.

Corbett, J. M.; Rasmussen, L. B.; and Rauner, F. Crossing The Border: The Social and Engineering Design of Computer Integrated Manufacturing Systems. London: Springer-Verlag, 1991.

Curtis, B., Krasner, H., and Iscoe, N. “A Field Study of the Software Design Process for Large Systems." Communications of the ACM, Volume 31, Number 11, November 1988.

Eason, K. D. "The Process of Introducing Information Technology." Behavior and Information Technology, Volume 1, Number 2, April-June 1982. Reprinted in R. Paton, S. Brown, R. Spear, J. Chapman, and J. Hamwee (Editors), Organizations: Cases, Issues and Concepts. London: Paul Chapman Publishing, London, 1984.

Galliers, R. D. “An Approach to Information Needs Analysis." In R. D. Galliers (Editor), Information Analysis. Reading, Massachusetts: Addison-Wesley, 1987.

Galliers, R. D., and Sutherland, A. R. "Information Systems Management and Strategy Formulation: The 'Stages Of Growth' Model Revisited." Journal of Information Systems, Volume 1, 1991, pp. 89-114.

Gasson, S. "Managing Organizational Change: The Impact of Information System Development Methods." In N. Jayaratna, G. Paton, Y. Merali, and F. Gregory (Editors), Proceedings of the Conference of the BCS Information Systems Methods Specialist Group. Heriot-Watt University, Edinburgh, September 1994.

Gasson, S. "User Involvement In Decision-Making In Information Systems Development." Proceedings of IRIS 18, Gjern, Denmark, August 1995.

Hardy, C.; Thompson, B.; and Edwards, H. "Method Use and Customization in the UK: A Preliminary Survey." In N. Jayaratna, G. Paton, Y. Merali, and F. Gregory (Editors), Proceedings of the Conference of the BCS Information Systems Methods Specialist Group, Heriot-Watt University, Edinburgh, September 1994.

Hedberg, B., and Mumford, E. 'The Design of Computer Systems: Man's Vision of Man as an Integral Part of the System Design Process." In E. Mumford and H. Sackman (Editors), Human Choice and Computers. Amsterdam: North-Holland, 1975.

Heller, F. A. "The Technological Imperative And The Quality Of Employment." New Technology, Work and Employment, 1987.

Hirschheim, R. A. "Information Systems Epistemology: An Historical Perspective." In R. D. Galliers (Editor), Information Systems Research: Issues, Methods and Practical Guidelines. Oxford: Blackwell Scientific, 1992. 
Hirschheim, R. A., and Klein, H. K. "Four Paradigms of Information Systems Development." Communications of the ACM, Volume 32, Number 10, 1989.

Hirschheim, R. A., and Klein, H. K. "Realizing Emancipatory Principles in Information Systems Development: The Case for ETHICS.” MIS Quarterly, March 1994, pp. 83-109

Hirschheim, R. A., and Klein, H. K. "A Research Agenda for Future Information Systems Development Methodologies." In W. W. Cotterman and J. A. Senn (Editors), Challenges and Strategies for Research in Systems Development. New York: John Wiley and Sons Ltd., 1992.

Hopker, O. "Evaluation and Choice of Information Systems Methodologies - A Welsh Perspective." In N. Jayaratna, G. Paton, Y. Merali, and F. Gregory (Editors), Proceedings of the Conference of the BCS Information Systems Methods Specialist Group, Heriot-Watt University, Edinburgh, September 1994.

Hornby, P.; Clegg, C. W.; Robson, J. I.; Maclaren, C. I.; Richardson, S. C.; and O’Brien, P. "Human and Organizational Issues In Information Systems Development." Behavior and Information Technology, Volume 11, Number 3, 1992.

Iivari, J. "A Methodology for IS Development as Organizational Change: A Pragmatic Contingency Approach." In H. K. Klein and K. Kumar (Editors), Systems Development for Human Progress, Proceedings of IFIP WG8.2. Amsterdam: North-Holland, 1987.

Jayaratna, N. "Guide To Method Understanding In Information Systems Practice." International Journal of Information Management, August 1988.

Jayaratna, N. Understanding and Evaluating Methodologies: A Systemic Framework. New York: McGraw Hill, 1994.

Kappelman, L. A; and McLean, E. R. "Promoting Information System Success: The Respective Roles of User Participation and User Involvement." Journal of Information Technology Management, Volume 3, Number 1, 1992, pp. 1-12.

Keen, P. G. W. "MIS Research: Current Status, Trends and Needs." In R. A. Buckingham, R. A. Hirschheim, F. F. Land, and C. J. Tully (Editors), Information Systems Education Cambridge: BCS, 1987.

Kumar, K., and Bjørn-Andersen, N. "A Cross-Cultural Comparison of IS Designer Values." Communications of the ACM, May 1990, Volume 33, Number 5, 1990, pp. 528-538.

Leavitt, L. Managerial Psychology. Chicago: University of Chicago Press, 1972.

Lyytinen, K. “A Taxonomic Perspective Of Information Systems Development Theory." In R. J. Boland, and R. A. Hirschheim (Editors), Critical Issues In Information Systems Research, London: Wiley, 1987. 
Markus, M. L., and Bjørn-Andersen, N. "Power Over Users: Its Exercise By System Professionals." Communications of the ACM, Volume 30, Number 6, June 1987.

Methlie, L. B. "Systems Requirements Analysis - Methods And Models." In H. C. Lucas Jr., F .F. Land, J .J. Lincoln and K. Supper (Editors), The Information Systems Environment, Proceedings of IFIP TC8.2 Working Conferences, Bonn 1979. Amsterdam: North Holland Publishing Company, 1980.

Morley, C. "Information Systems Development Methods and User Participation: A Contingency Approach." In D. Avison, J. E. Kendall, and J. I. DeGross (Editors), Human, Organizational and Social Dimensions of Information Systems Development: Proceedings of IFIP WG8.2 Conference, Noorwijkerhout, The Netherlands. Amsterdam: North Holland, 1993.

Mumford, E., and Henshall, D. Designing Participatively. Manchester, England: Manchester Business School, 1983.

Scott Morton, M. S. "Introduction." In M. S. Scott Morton (Editor), The Corporation of the 1990s. New York: Oxford University Press, 1991.

Vitalari, N. P. "A Critical Assessment of Structured Analysis Methods: A Psychological Perspective" In T. M. A. Bemelmans (Editor), Beyond Productivity: Information Systems Development For Organizational Effectiveness. Amsterdam: North-Holland, 1984.

Wynekoop, J. L., and Russo, N. L. "System Development Methodologies: Unanswered Questions and the Research-Practice Gap." In J. I. DeGross, R. P. Bostrom, and R. D. Robey (Editors), Proceedings of the Fourteenth International Conference on Information Systems. Orlando, Florida, December 1993.

\section{About the Authors}

Susan Gasson is a Lecturer in Information Systems at Warwick Business School. Her research interests include software development process modeling, the development of human-centered approaches to information system design, and the impact of IT on effective organizational work. Prior to joining Warwick Business School she worked as a data communications consultant, specializing in the design of Open Systems.

Niki Holland is a founding consultant of Transition Partnerships, a consultancy which helps people and organizations to manage their own change. It has developed its own approach to managing IT-related change which integrates IS design with the design of work and organizational systems, facilitating user commitment to change. 


\section{APPENDIX: SURVEY QUESTIONS}

1. How would you describe the system architecture in your organization? (Tick as many as apply).

1. Stand-alone PCS

2. Workstations - connected by a Local Area Network

3. Workstations - connected by a Wide Area Network

4. Minicomputer - with dumb terminals
5. Client/server architecture

6. Mainframe - with PC links

7. IT links to customers

8. IT links to suppliers

2. To what extent are the following true of your organization?

\section{False}

Business functions can access applications from a network Business functions can extract data from central databases to use local

$\begin{array}{lllll}1 & 2 & 3 & 4 & 5\end{array}$

$\begin{array}{lllll}1 & 2 & 3 & 4 & 5\end{array}$

applications

Business functions have access to integrated office systems

$\begin{array}{lllll}1 & 2 & 3 & 4 & 5\end{array}$

3. Think about the main IT development project as a whole. What did it most resemble?

1. A single, staged life-cycle.

2. A Set of evolutionary developments

4. What was the duration of the main IT development project?
1. < 1 year
5. -4 years
2. -2 years
6. -6 years
3. -3 years
7. $>5$ years

5. Now think about the approach to system development during the main IT development project. How would you rate the following factors?

The overall emphasis was on:

The approach to system requirements definition stressed

The approach to system design and modeling stressed:

$$
\begin{array}{rrl}
\begin{array}{r}
\text { Exploiting technical } \\
\text { opportunities } \\
\text { Business }
\end{array} & 1234567 & \begin{array}{l}
\text { Supporting organi- } \\
\text { zational changes }
\end{array} \\
\begin{array}{r}
\text { requirements } \\
\text { Financial require- }
\end{array} & 1234567 & \begin{array}{l}
\text { Technical } \\
\text { infrastructures } \\
\text { Modeling work } \\
\text { processes }
\end{array}
\end{array}
$$

6. Think of the methods and tools used in the main IT development project for project management and system development. What tools were used at each of the following 3 stages? (Open question)

A. Requirements Analysis

\begin{tabular}{|l|l|}
\hline Project Management & System Development \\
\hline
\end{tabular}

B. System Design

\begin{tabular}{|l|ll|}
\hline Project Management & System Development \\
\hline & C. Implementation \\
\hline Project Management & System Development \\
\hline
\end{tabular}


7. Think about the approach to business needs definition. Which of the following mechanisms were used to match IS needs to business needs?

(N.B. Mechanisms were derived from the first author's experience as a System Designer).

A. During system requirements analysis

1. Validation and sign-off of specifications by users

2. Participation of users at requirements "walk throughs"

3. User-participation workshops

4. Interviews with users to elicit requirements

5. Joint design (using groups of users to design work processes)

6. Participation of users as development team members.

C. During system implementation and testing

1. Provision of user manual $\mathbf{s}$

2. Provision of help-desk facilities to support user problems

3. Formal user training in use of the new systems

4. User workshops to discuss design changes

5. User-directed testing schedules

6. Modifications to system design to support business applications

\section{B. During system design}

1. User validation and sign-off of design documents

2. User attendance at design "walk-throughs"

3. Use of experimental system prototypes (to try out ideas)

4. Use of evolutionary system prototypes (incorporated into system)

5. Formal user training in use of development tools

D. During ongoing operation of system

1. User manuals describing advanced system features

2. Formal advanced training in use of the system

3. Use of methods to help users re-design work processes

4. Modifications to system design to support business applications.

5. User-support mechanisms for dissemination of information about the new system.

8. Think about the overall change of which this project was a part. To what extent did the following factors get in the way of, or help the success of, the change?

\begin{tabular}{|c|c|c|c|c|c|c|c|}
\hline User consultation and involvement & Really got in the way & 12 & 34 & & & & Helped a great deal \\
\hline $\begin{array}{l}\text { Approaches to planning and } \\
\text { project management }\end{array}$ & Really got in the way & 12 & 34 & 5 & & 1 & Helped a \\
\hline
\end{tabular}

9. Think about the IT aspects of the change process. What do you feel ...
A. ... you did well?
B. ... you should do differently next time?
C. ... are the aspects of a well-managed change process that you missed altogether? 